\title{
Trend Analysis of Temperature and Rainfall of Rajasthan, India
}

\author{
Suresh Kumar Sharma $\mathbb{D}^{1},{ }^{1}$ Durga Prasad Sharma $\mathbb{D}^{2},{ }^{2}$ Manoj Kumar Sharma $\mathbb{D},^{3}$ \\ Kiran Gaur $\mathbb{D}^{3}{ }^{3}$ and Pratibha Manohar $\mathbb{D D}^{3}$ \\ ${ }^{1}$ MSRDC-Maharishi Arvind Institute of Science and Management, Jaipur Under RTU Kota, SKN College of Agriculture, \\ Jobner 303329, Rajasthan, India \\ ${ }^{2}$ MSRDC-MAISM (RTU), Research Centre Jaipur \& AMUIT, MOEFDRE Under UNDP, Ethiopia \\ ${ }^{3}$ SKN College of Agriculture, Jobner 303329, Rajasthan, India \\ Correspondence should be addressed to Durga Prasad Sharma; dp.shiv08@gmail.com
}

Received 12 July 2021; Revised 18 November 2021; Accepted 6 December 2021; Published 22 December 2021

Academic Editor: Marek T. Malinowski

Copyright ( 2021 Suresh Kumar Sharma et al. This is an open access article distributed under the Creative Commons Attribution License, which permits unrestricted use, distribution, and reproduction in any medium, provided the original work is properly cited.

\begin{abstract}
Increasing temperature and declining and erratic rainfall is one of the greatest global challenges. This study presents the trend analysis of temperature and rainfall in five divisional headquarters of Rajasthan, namely, Bikaner, Jaipur, Jodhpur, Kota, and Udaipur. The historic data of minimum and maximum temperature and rainfall for a period of 49 years from 1971 to 2019 were collected from Climate Research and Services, India Meteorological Department, Pune. Detection of trends and change in magnitude was done using the Mann-Kendall (MK) test and Sen's slope, respectively. The results of the study indicated a significant increase in both minimum and maximum temperature over time for all the five stations. However, rainfall showed a nonsignificant increasing trend for Kota and Udaipur district, whereas Bikaner, Jaipur, and Jodhpur detected a negative trend.
\end{abstract}

\section{Introduction}

Climate change is the most vulnerable change taking place worldwide. It directly or indirectly impacts our ecosystem, cropping system, lives, and livelihood of the society. The study of change in max and min temperatures as well as rainfall plays a key role in recognizing the adverse impact of change of climate to improve management practices to attain environmental sustainability into development planning. The first step to attain sustainability in terms of climate is to take observations, identifying threat areas and vulnerable regions and sectors. The research outputs and recommendations are needed to be added to the state and national policies. Subhash and Sikka [1] examined the fact about the rational relationships of trends between rainfall and temperature over the homogenous regions in India. It found no direct relationship among increasing max temperature and increasing rainfall or seasonwise trend over meteorological subdivisions of India. However, it was concluded that the relation has wide scale temporal and spatial dependence. Both rainfall and temperature are critical considerations of crop yield; therefore, precise simulation of these variables is important for agricultural economics as well as meteorology. However, in general, it is difficult to simulate temperature and rainfall simultaneously due to the high correlation between them $[2,3]$. Meshram et al. [4] studied long-term rainfall data of Ken River basin, Central India, over the period 1901-2010; the study was centred on water resource planning for agriculture and provided useful results for sustainable water utilization policy making. Another study was conducted by Jain and Kumar [5] to review trend of rainy days, rainfall, and temperature across India. Sen's slope was used to evaluate the magnitude of trend followed by statistical significance done by the MK test. The mean max temperature showed an increasing trend, whereas mean min temperature was found increasing as well as decreasing over different areas. Gajbhiye et al. [6] studied precipitation trend of Sindh River basin, India, for the data of 102 years ranging from 1901 to 2002, and found significant increase in the trend in seasonal and annual rainfall in these years. It is thus imperative to undertake a systematic study of rainfall and temperature 
trends for farming policies associated with long-term planning in agriculture and related sectors, food security, energy security, tourism, and many commercial entities that are directly related to these two weather parameters.

In India, climate change is causing adverse impact on monsoon timing, temperature, and other weather parameters, thus imposing potential impacts on the atmosphere [7]. Even a marginal increase in temperature can result in heatwave incidents and serious damage and alterations in species of animals and plants [8]. Several researchers have concluded that the pattern and extent of warming over India or the Indian subcontinent over the previous century are comprehensively steady with the worldwide pattern and magnitude [9-11]. Mohammad and Goswami [12] worked on the temperature and precipitation data of 115 years duration from 1901 to 2015, for 139 major Indian cities of India, and found decreasing trend in northwest cities and increasing trend in southeast cities with regards to temperature and quite heterogeneous patterns of trend in the rainfall data with decreasing rainfall in eastern part as compared to the western part.

Global climate has changed sharply in recent decades and exposed a significant impact on social and economic wellbeing as well as on the environment putting our living and physical environment into remarkable and multidimensional risk $[13,14]$. Local climatic data assessment helps to understand the risks associated with climatic variability. The trend of rainfall and temperature was analyzed by Khavse et al. [15] using meteorological data of years 1971-2013 for Raipur district of Chhattisgarh. The linear trend analysis showed a long-term change in rainfall and temperature using the MK test. A modelling was done through data mining techniques using knowledge discovery in the database process model for Ethiopia by designing for weather variability forecasting, and it was found to be $98 \%$ accurate [16].

It has been observed that the trend analysis of weather variability parameters is not frequently in use in the state of Rajasthan, and no such study has been reported previously for the region depicting past trends of weather parameters. The present study will be helpful in deciding the appropriate cropping pattern and water resource planning for agriculture at the study location; parallelly, it will also help to develop strategies for reducing the biotic and abiotic stress during crop production. However, the study has a limitation that only three weather parameters have been considered presently. If the data on crop productivity and other weather variables were also considered, a more reliable picture of the study had been produced.

As per observations, adaptive capacity of climate resilience is quite low in Rajasthan, whereas it suffers with high climatic sensitivity. Studies show that the climate change in Rajasthan is over and above the climatic variability. To deal with these issues, Climate Change Agenda for Rajasthan (CCAR) was formed under Rajasthan Environment Policy released in 2010. To incorporate CCAR, Rajasthan Environment Mission was set with major emphasis on several key areas during 2010-2014. The reports of Rajasthan State Action Plan on Climate Change say that the state is already dealing with water scarcity with highest chances of drought occurrences with a frequency of almost four out of every five years with extremely low and erratic rainfall and limited surface water resources. Climate change is thus one of the greatest threats to Rajasthan, and it is thus always starving to find best strategies to deal with the adverse situations occurring due to climate change. The present study is performed with an aim to assist in policy making on what can be an effective strategy for communicating the issue of climate resilience in Rajasthan, so that urgent areas of action may be identified.

\section{Data and Methodology}

The climate of Rajasthan: being the biggest, the territory of Rajasthan is particularly prone to the threat of climatic limits. The state has been perceived as one of the four most vulnerable states because of environmental change by the State Action Plan on Climate Change. It has $66 \%$ of its space as the Thar Desert is especially portrayed by low and inconsistent rainfall, high air and soil temperature, exceptional sunpowered radiation, and high wind speed. The situating of the great Aravalli runs neglects to make any orographic rainfall and corresponds to the cloud bearing breezes in the state during the rainstorm months. The Tropic of Cancer brings about high temperatures throughout the late spring. The arid and semiarid regions of the state experience high daily and occasional fluctuations in temperature. The midyear temperature averages around a range of $26-46^{\circ} \mathrm{C}$. In winter, the temperature varies from $8^{\circ} \mathrm{C}$ to $28^{\circ} \mathrm{C}$. The yearly rainfall aggregates to around $600 \mathrm{~mm}$ in the eastern and southeastern parts and just $100 \mathrm{~mm}$ in the western regions of the state.

2.1. Study Area. India's largest area occupying state Rajasthan is located in the northwestern part of the subcontinent. The areas selected for this study are Bikaner, Jaipur, Kota, Jodhpur, and Bikaner districts of Rajasthan which are the divisional headquarters of the state. The adjoining districts of these headquarters cover almost entire state, and climate change can be accessed for the state. The area of study and geographical position of selected districts are shown in Figure 1 , and land details of the research area are given in Table 1.

2.2. Datasets. For this study, the historical data from the year 1971 to 2019 (49 years) were collected for rainfall, $\min$ temperature, and $\max$ temperature for Bikaner, Jaipur, Kota, Jodhpur, and Bikaner districts of Rajasthan [17]. The annual total rainfall and mean of min and max temperature were calculated and processed in Excel sheets to examine the trends and further analysis. The weather data from 1971 to 2015 were collected from the portal of Climate Research and Services India Meteorological Department, Pune, while the latest data of the period of 2015-2019 were obtained from the publication of Rainfall Statistics of India-2015-2019 [18].

2.3. Methodology. The data obtained from the above sources were tabulated and summary statistics, namely, mean, standard deviation (SD), and coefficient of variation (CV) were reported. For detecting the trends, time series graphs were plotted, and Mann-Kendall's test was used for the selected variables. 


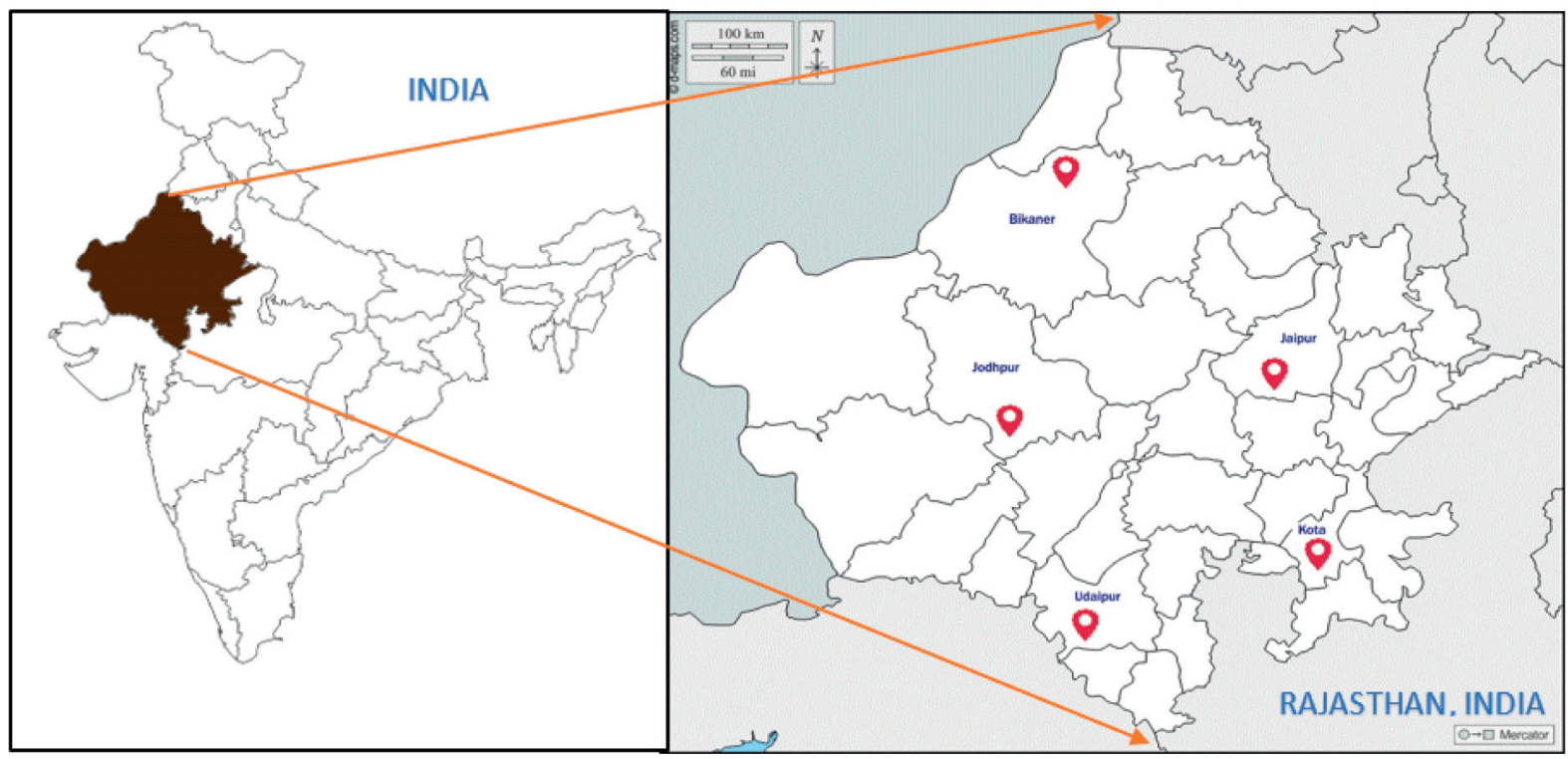

Figure 1: Map of the study area.

TABLE 1: The land details of the study area.

\begin{tabular}{lcccc}
\hline District & Latitude & Longitude & Area (sq. kms) & $\begin{array}{c}\text { \% area of the } \\
\text { state }\end{array}$ \\
\hline Bikaner & $28^{\circ} 01^{\prime} \mathrm{N}$ & $73^{\circ} 22^{\prime} \mathrm{E}$ & 30247 & 8.84 \\
Jaipur & $26^{\circ} 55^{\prime} \mathrm{N}$ & $75^{\circ} 52^{\prime} \mathrm{E}$ & 11152 & 3.26 \\
Kota & $25^{\circ} 10^{\prime} \mathrm{N}$ & $75^{\circ} 52^{\prime} \mathrm{E}$ & 5098 & 1.49 \\
Jodhpur & $26^{\circ} 18^{\prime} \mathrm{N}$ & $73^{\circ} 04^{\prime} \mathrm{E}$ & 22850 & 6.68 \\
Udaipur & $27^{\circ} 42^{\prime} \mathrm{N}$ & $75^{\circ} 33^{\prime} \mathrm{E}$ & 12596 & 3.68 \\
\hline
\end{tabular}

2.4. The Mann-Kendall's Trend Test. The significance of the trends was tested by a nonparametric test known as the Mann-Kendall (MK) test. It identifies trends in the data of time series. The test was introduced by Mann [19] and Kendall [20] and has been widely used in environmental time series [21]. The test compares the relative magnitudes of the sample data as well as the data values themselves.

Let $x_{1}, x_{2}, \ldots, x_{n}$ represent $n$ data points, where $x_{j}$ represents the data point at time $j$. The Mann-Kendall statistic $(\mathrm{S})$ is given by

$$
S=\sum_{i=1}^{n-1} \sum_{j=i+1}^{n} \operatorname{sign}\left(x_{j}-x_{i}\right),
$$

where sign is the well-known signum function. If either $x_{j}$ or $x_{i}$ is missing, then $\operatorname{sign}\left(x_{j}-x_{i}\right)=0$ as per definition.

The trend is tested by calculating the test statistic

$$
Z= \begin{cases}\frac{S-1}{(\operatorname{var}(S))^{1 / 2}}, & S>0, \\ 0, & S=0, \\ \frac{S+1}{(\operatorname{var}(S))^{1 / 2}}, & S<0 .\end{cases}
$$

For a sample size $>10$, a normal approximation to the MK test may be used. Variance of $S$ is obtained as

$$
\operatorname{var}(S)=\frac{n(n-1)(2 n+5)}{18}
$$

where $n$ is the number of loads in the time series.

A very high positive value of $S$ means an increasing trend, and a very low negative value represents a trend of decreasing nature. However, the statistical significance of the trend was tested by $P$ value. A $P$ value less than 0.05 was considered significant.

The slope within the time series was estimated by the formula proposed by Sen [22] and is given by Sen's slope estimator.

For all pairs of observations $\left(x_{i}, x_{j}\right)$ with $1 \leq j<i \leq n$,

$$
d_{i j}=\frac{x_{i}-x_{j}}{i-j}
$$

2.5. Analysis Tools. We used Statistical Package for the Social Sciences (SPSS) package (trial version) for calculating descriptive statistics. Graphs were plotted using the polynomial regression function in Microsoft Excel and Mann-Kendall test, and Sen's slope was calculated using XLSTAT (trial version) package. XLSTAT is a statistical tool that allows to gain deep insight into your data and used for data preparation and visualization tools, parametric and nonparametric tests, modelling methods such as ANOVA, regression, generalized linear models, nonlinear models, data mining features such as principal component analysis, correspondence analysis, and clustering methods (agglomerative hierarchical clustering, K-means). 
TABLE 2: Summary statistics for annual rainfall in mm (1971-2019) in the districts of Rajasthan.

\begin{tabular}{|c|c|c|c|c|c|c|c|c|c|c|c|c|c|c|c|}
\hline \multicolumn{3}{|c|}{ Bikaner } & \multicolumn{3}{|c|}{ Jaipur } & \multicolumn{3}{|c|}{ Jodhpur } & \multicolumn{3}{|c|}{ Kota } & \multicolumn{3}{|c|}{ Udaipur } & \multirow[b]{2}{*}{$\mathrm{CV}$} \\
\hline Month & Mean & SD & $\mathrm{CV}$ & Mean & SD & $\mathrm{CV}$ & Mean & SD & $\mathrm{CV}$ & Mean & SD & $\mathrm{CV}$ & Mean & SD & \\
\hline January & 4.3 & 5.8 & 134.9 & 5.7 & 8.1 & 142.1 & 3.3 & 7 & 212.1 & 5.7 & 10.8 & 189.5 & 2.6 & 6.3 & 242.3 \\
\hline February & 10.2 & 8.3 & 81.4 & 10.1 & 9.1 & 90.1 & 5.1 & 6.2 & 121.6 & 6.9 & 9 & 130.4 & 2.5 & 4.8 & 192.0 \\
\hline March & 7.4 & 8 & 108.1 & 5.6 & 8.1 & 144.6 & 2 & 5.2 & 260.0 & 6.1 & 8.2 & 134.4 & 1.8 & 4 & 222.2 \\
\hline April & 8.3 & 8.1 & 97.6 & 10.5 & 8.8 & 83.8 & 9.2 & 6.4 & 69.6 & 4.5 & 7.4 & 164.4 & 5 & 4.3 & 86.0 \\
\hline May & 23.5 & 12.8 & 54.5 & 17 & 10.9 & 64.1 & 19.6 & 10.5 & 53.6 & 10.6 & 8.2 & 77.4 & 16 & 8.1 & 50.6 \\
\hline June & 42.1 & 20.8 & 49.4 & 65.1 & 28.4 & 43.6 & 46 & 21.1 & 45.9 & 72.4 & 30.5 & 42.1 & 72.7 & 30.6 & 42.1 \\
\hline July & 93 & 40 & 43.0 & 200 & 80 & 40.0 & 129.4 & 52.7 & 40.7 & 250.5 & 98.8 & 39.4 & 187.5 & 76.3 & 40.7 \\
\hline August & 62.2 & 43.4 & 69.8 & 191.5 & 100.9 & 52.7 & 126.2 & 66.5 & 52.7 & 243.2 & 126.2 & 51.9 & 204.6 & 101.6 & 49.7 \\
\hline September & 33.4 & 42.4 & 126.9 & 61.4 & 97.3 & 158.5 & 51 & 64.9 & 127.3 & 86.7 & 122.5 & 141.3 & 91.2 & 100.5 & 110 \\
\hline October & 13.1 & 40.5 & 309.2 & 19.1 & 92.6 & 484.8 & 6.6 & 61.6 & 933.3 & 19.5 & 116.4 & 596.9 & 13 & 95.4 & 733.8 \\
\hline November & 2 & 38.6 & 1930.0 & 4.9 & 88.3 & 1802.0 & 2.9 & 58.8 & 2027.6 & 8 & 111 & 1387.5 & 12.5 & 91.1 & 728.8 \\
\hline December & 1.6 & 36.9 & 2306.3 & 3 & 84.5 & 2816.7 & 1.6 & 56.3 & 3518.8 & 3.2 & 106.3 & 3321.9 & 1.9 & 87.2 & 4589.5 \\
\hline
\end{tabular}

TABLe 3: Summary statistics for min temperature in ${ }^{\circ} \mathrm{C}$ (1971-2019) in the districts of Rajasthan.

\begin{tabular}{|c|c|c|c|c|c|c|c|c|c|c|c|c|c|c|c|}
\hline \multicolumn{3}{|c|}{ Bikaner } & \multicolumn{3}{|c|}{ Jaipur } & \multicolumn{3}{|c|}{ Jodhpur } & \multicolumn{3}{|c|}{ Kota } & \multicolumn{3}{|c|}{ Udaipur } & \multirow[b]{2}{*}{$\mathrm{CV}$} \\
\hline Month & Mean & SD & $\mathrm{CV}$ & Mean & SD & $\mathrm{CV}$ & Mean & SD & $\mathrm{CV}$ & Mean & $\mathrm{SD}$ & $\mathrm{CV}$ & Mean & SD & \\
\hline January & 7.0 & 1.7 & 24.3 & 8.3 & 1.6 & 19.3 & 9.3 & 1.8 & 19.4 & 10.9 & 2.5 & 22.9 & 6.8 & 2.4 & 35.3 \\
\hline February & 10.6 & 7.6 & 71.7 & 11.3 & 8.1 & 71.7 & 11.9 & 8.5 & 71.4 & 13.7 & 9.8 & 71.5 & 8.6 & 6.3 & 73.3 \\
\hline March & 16.5 & 11.4 & 69.1 & 16.7 & 11.7 & 70.1 & 17.4 & 12.2 & 70.1 & 19.1 & 13.6 & 71.2 & 14.2 & 9.7 & 68.3 \\
\hline April & 22.7 & 15.0 & 66.1 & 22.3 & 15.0 & 67.3 & 23.1 & 15.6 & 67.5 & 25.0 & 17.2 & 68.8 & 19.7 & 12.9 & 65.5 \\
\hline May & 27.3 & 18.2 & 66.7 & 26.4 & 17.9 & 67.8 & 27.1 & 18.5 & 68.3 & 29.1 & 20.1 & 69.1 & 24.3 & 15.9 & 65.4 \\
\hline June & 29.2 & 20.4 & 69.9 & 27.5 & 19.8 & 72.0 & 27.7 & 20.3 & 73.3 & 28.6 & 21.8 & 76.2 & 25.1 & 17.7 & 70.5 \\
\hline July & 27.1 & 21.5 & 79.3 & 25.4 & 20.7 & 81.5 & 26.9 & 21.4 & 79.6 & 25.6 & 22.4 & 87.5 & 23.6 & 18.7 & 79.2 \\
\hline August & 27.1 & 22.3 & 82.3 & 24.2 & 21.2 & 87.6 & 25.6 & 22.0 & 85.9 & 24.5 & 22.6 & 92.2 & 22.9 & 19.3 & 84.3 \\
\hline September & 25.3 & 22.6 & 89.3 & 23.6 & 21.5 & 91.1 & 23.9 & 22.2 & 92.9 & 24.3 & 22.8 & 93.8 & 19.8 & 19.3 & 97.5 \\
\hline October & 19.7 & 22.4 & 113.7 & 19.3 & 21.3 & 110.4 & 19.1 & 21.9 & 114.7 & 20.9 & 22.6 & 108.1 & 16.5 & 19.1 & 115.8 \\
\hline November & 13.1 & 21.7 & 165.6 & 13.7 & 20.7 & 151.1 & 14.4 & 21.3 & 147.9 & 15.9 & 22.1 & 139.0 & 11.7 & 18.5 & 158.1 \\
\hline December & 8.1 & 20.9 & 258.0 & 9.3 & 20.0 & 215.1 & 10.4 & 20.6 & 198.1 & 12.2 & 21.5 & 176.2 & 8.1 & 17.9 & 221.0 \\
\hline
\end{tabular}

\section{Results and Discussion}

We used both monthly and annually data to calculate the mean, standard deviation (SD), and coefficient of variation (CV) of rainfall, min, and max temperature. The monthwise basic statistical attributes of selected variables are presented in the subsequence tables for the five stations separately.

The figures for mean rainfall presented in Table 2 indicate that the region received less to scarce rainfall even in rainy season. The highest rainfall was observed in the months of July and August with less value of CV. Kota, Jaipur, and Udaipur received an average rainfall of more than $200 \mathrm{~mm}$ in monsoon months, whereas Bikaner received lowest rainfall with an average of $93 \mathrm{~mm}$ and $62.2 \mathrm{~mm}$ in the month of July and August. A further mining of data showed that the highest mean rainfall of $424.1 \mathrm{~mm}$ was received in the month of August during the year 1973 for Jodhpur district. In Kota, the rainfall as high as $675.8 \mathrm{~mm}$ was received in the year 2001. Similar figure was $630.0 \mathrm{~mm}$ in 1973 , $256.1 \mathrm{~mm}$ in 1978, and $956.3 \mathrm{~mm}$ in 1981 for Udaipur, Bikaner, and Jaipur, respectively, in the month of July.

It is clear from Table 3 that the min temperature varied from $6.8 \mathrm{C}$ in January to $29.2 \mathrm{C}$ in June for all the selected stations of the states. Udaipur and Bikaner were found to be the coldest districts, whereas Kota showed a high value of min temperature throughout the year. The analysis further showed that the years 1988, 1994, 2008, 2009, and 2016 were comparatively hot as far as min temperature was concerned, where the highest min temperature was recorded more than $10 \mathrm{C}$ for all the districts of Rajasthan.

It is evident from Table 4 that May is the hottest month of the year in the state where the max temperature shoots up to as high as about $42 \mathrm{C}$. Udaipur recorded lowest max temperature of $38.1 \mathrm{C}$, which may be because of its geographical location. Bikaner and Kota faced high mean temperature as compared to other districts. The analysis of mean monthly data further revealed that Kota and Bikaner recorded highest mean max temperature of $44.5 \mathrm{C}$ in the year 2010 and 1978, respectively. Jaipur and Udaipur noted hottest in May in the year 1988, whereas Jodhpur observed the highest temperature of $43.1 \mathrm{C}$ in the year 1998. The annual trends of min and max temperature and rainfall are represented through trendline graphs in Figure 2.

The MK test and Sen's slope were used to access the trends for min and max temperature and rainfall. Separate trend analysis was carried out on the selected variables, and the results of MK test along with the $P$ value and Sen's slope giving the magnitude of trend are given in Table 5 . It is evident from the table that a significant increasing trend exists for min temperature with $P$ value $<0.05$ at all the five stations except Kota $(P$ value $=0.06)$ where the increase was not observed to be significant at $5 \%$ level of significance. Max 
TABle 4: Summary statistics for max temperature in C (1971-2019) in the districts of Rajasthan.

\begin{tabular}{|c|c|c|c|c|c|c|c|c|c|c|c|c|c|c|c|}
\hline \multicolumn{3}{|c|}{ Bikaner } & \multicolumn{3}{|c|}{ Jaipur } & \multicolumn{3}{|c|}{ Jodhpur } & \multicolumn{3}{|c|}{ Kota } & \multicolumn{3}{|c|}{ Udaipur } & \multirow[b]{2}{*}{$\mathrm{CV}$} \\
\hline Month & Mean & SD & $\mathrm{CV}$ & Mean & $\mathrm{SD}$ & $\mathrm{CV}$ & Mean & SD & $\mathrm{CV}$ & Mean & $\mathrm{SD}$ & $\mathrm{CV}$ & Mean & $\mathrm{SD}$ & \\
\hline January & 23.2 & 3.5 & 15.1 & 22.5 & 3.5 & 15.6 & 25.2 & 3.8 & 15.1 & 22.8 & 4.9 & 21.5 & 22.7 & 7.1 & 31.3 \\
\hline February & 26.4 & 18.9 & 71.6 & 25.5 & 18.2 & 71.4 & 28.1 & 20.1 & 71.5 & 26.2 & 18.9 & 72.1 & 24.2 & 17.8 & 73.6 \\
\hline March & 32.4 & 24.2 & 74.7 & 31.6 & 23.5 & 74.4 & 33.8 & 25.5 & 75.4 & 32.4 & 24.2 & 74.7 & 30.9 & 23 & 74.4 \\
\hline April & 38.4 & 28.5 & 74.2 & 37.4 & 27.7 & 74.1 & 38.8 & 29.4 & 75.8 & 38.3 & 28.4 & 74.2 & 36 & 26.9 & 74.7 \\
\hline May & 42 & 31.6 & 75.2 & 40.7 & 30.7 & 75.4 & 40.4 & 31.9 & 79.0 & 41.5 & 31.5 & 75.9 & 38.1 & 29.5 & 77.4 \\
\hline June & 41.6 & 33.5 & 80.5 & 39.4 & 32.3 & 82.0 & 40 & 33.4 & 83.5 & 39.1 & 32.9 & 84.1 & 35.6 & 30.6 & 86.0 \\
\hline July & 36.8 & 34 & 92.4 & 33.6 & 32.5 & 96.7 & 35.9 & 33.8 & 94.2 & 32.6 & 32.8 & 100.6 & 30.6 & 30.6 & 100.0 \\
\hline August & 37 & 34.4 & 93.0 & 31.9 & 32.4 & 101.6 & 33.9 & 33.8 & 99.7 & 30.7 & 32.6 & 106.2 & 29.7 & 30.5 & 102.7 \\
\hline September & 37.2 & 34.7 & 93.3 & 34.1 & 32.6 & 95.6 & 35.4 & 34 & 96.0 & 32.6 & 32.6 & 100.0 & 29.4 & 30.4 & 103.4 \\
\hline October & 35.5 & 34.8 & 98.0 & 33.2 & 32.7 & 98.5 & 35.4 & 34.1 & 96.3 & 32.3 & 32.5 & 100.6 & 31.9 & 30.5 & 95.6 \\
\hline November & 30.5 & 34.4 & 112.8 & 28.8 & 32.3 & 112.2 & 31.1 & 33.8 & 108.7 & 28.7 & 32.2 & 112.2 & 28.9 & 30.4 & 105.2 \\
\hline December & 25.1 & 33.8 & 134.7 & 24.2 & 31.7 & 131.0 & 26.7 & 33.3 & 124.7 & 24.9 & 31.7 & 127.3 & 25.2 & 30 & 119.0 \\
\hline
\end{tabular}
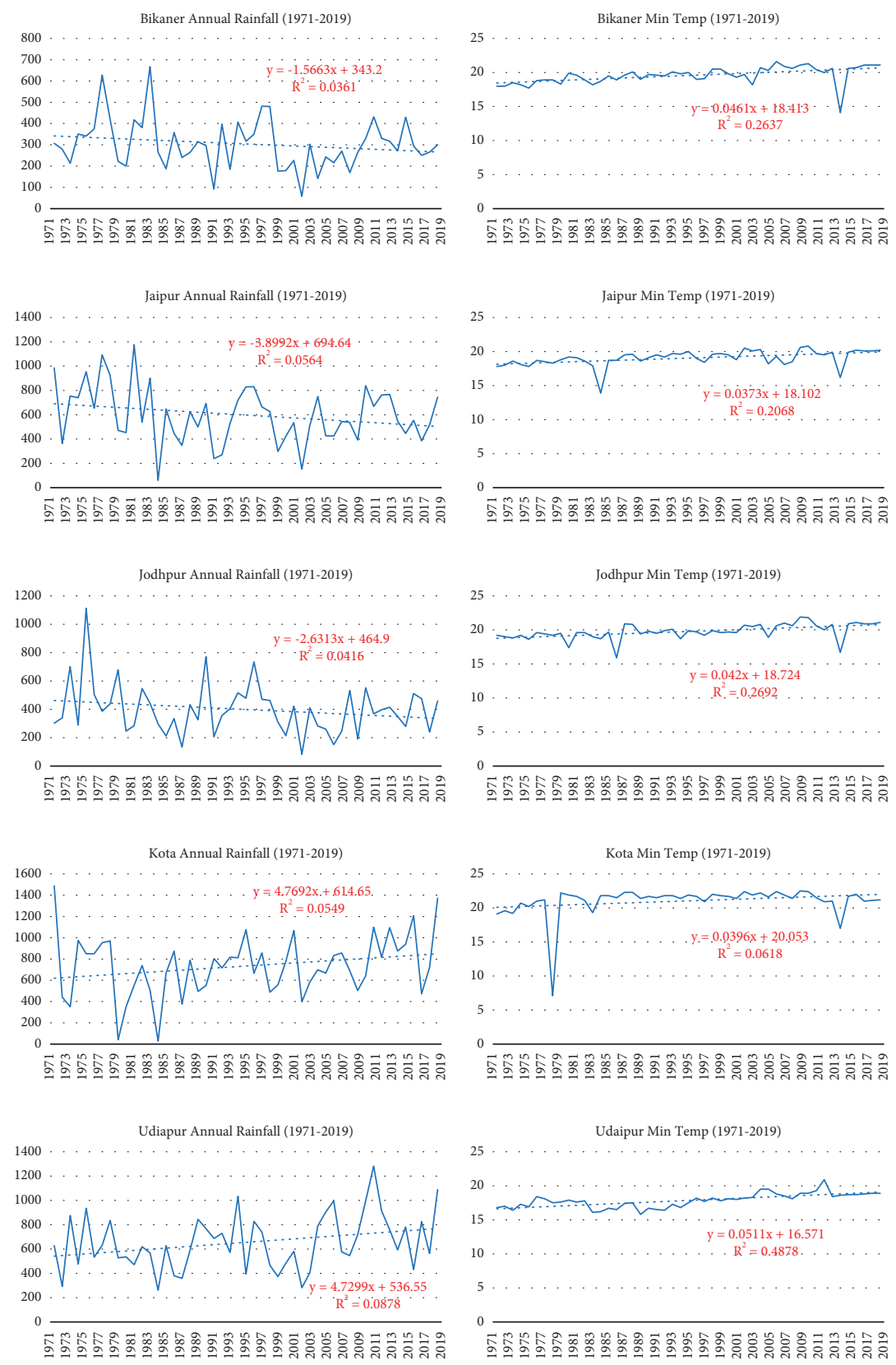
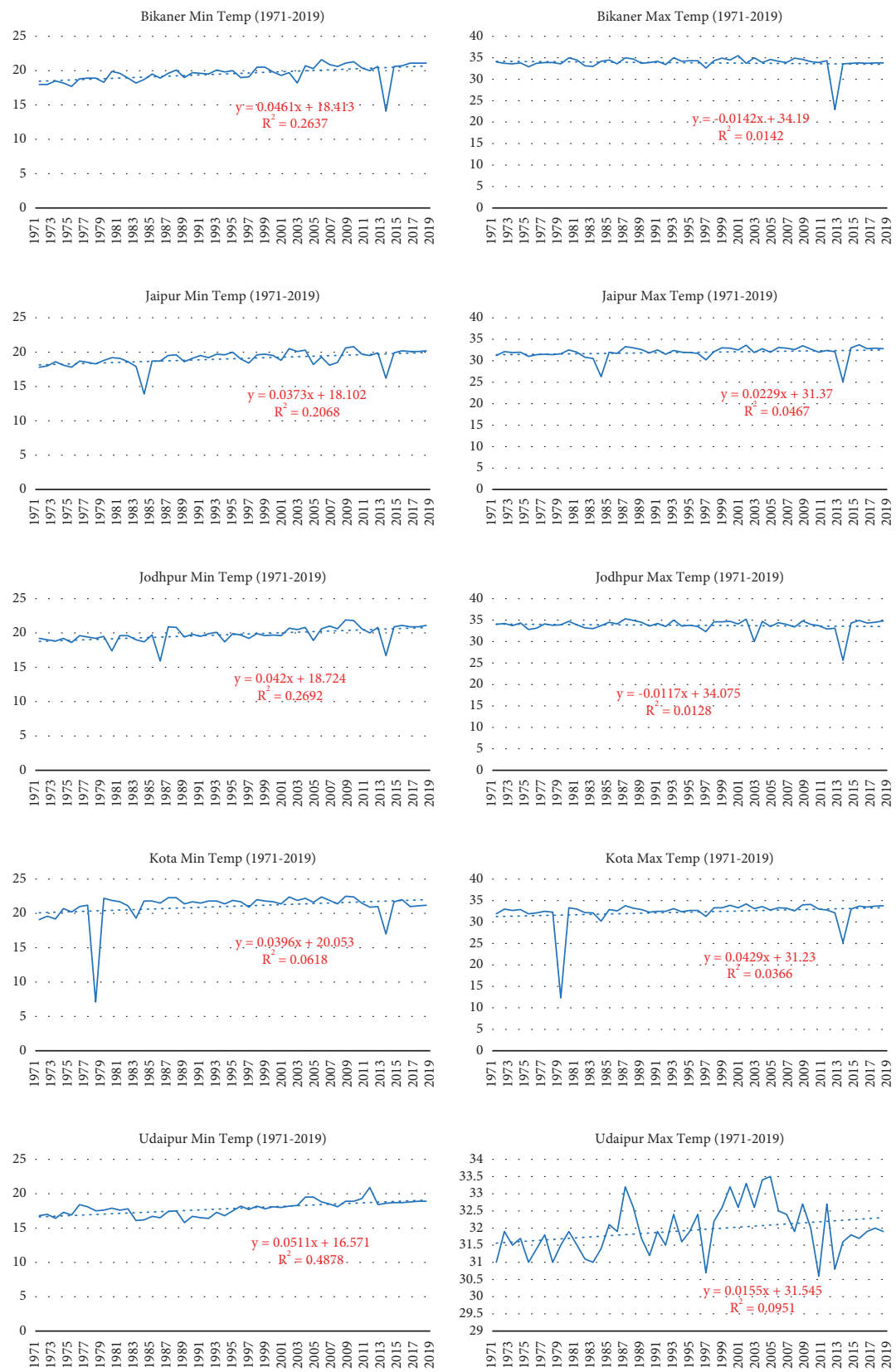

Figure 2: Annual trends of rainfall, min, and max temperature from 1971 to 2019. 
TABLE 5: Trend analysis of temperature and rainfall using the MK test (at 5\% level of significance).

\begin{tabular}{|c|c|c|c|c|c|c|c|c|c|c|c|c|}
\hline \multirow[b]{2}{*}{ Station } & \multicolumn{4}{|c|}{ Temperature (min) } & \multicolumn{4}{|c|}{ Temperature $(\max )$} & \multicolumn{4}{|c|}{ Rainfall } \\
\hline & $\begin{array}{c}\mathrm{S} \\
\text { statistic }\end{array}$ & $\begin{array}{l}\text { Value } \\
(P)\end{array}$ & $\begin{array}{l}\text { Sen } \\
\text { slope }\end{array}$ & Trend & $\begin{array}{c}\mathrm{S} \\
\text { statistic }\end{array}$ & $\begin{array}{l}\text { Value } \\
\qquad(P)\end{array}$ & $\begin{array}{l}\text { Sen } \\
\text { slope }\end{array}$ & Trend & $\begin{array}{c}\mathrm{S} \\
\text { statistic }\end{array}$ & $\begin{array}{l}\text { Value } \\
\qquad(P)\end{array}$ & $\begin{array}{l}\text { Sen } \\
\text { slope }\end{array}$ & Trend \\
\hline Bikaner & 644 & 0.00 & 0.05 & Increasing & 65 & 0.57 & 0.001 & Incre & -104 & 0.37 & -1.07 & Decreasing \\
\hline Jaipur & 549 & 0.00 & 0.04 & Increasing & 428 & 0.00 & 0.029 & Increasing & -145 & 0.21 & -3.69 & Decreasing \\
\hline Jodhpur & 595 & 0.00 & 0.04 & Increasing & 75 & 0.51 & 0.006 & Increasing & -99 & 0.39 & -1.35 & Decreasing \\
\hline Kota & 217 & 0.06 & 0.02 & Increasing & 392 & 0.00 & 0.025 & Increasing & 199 & 0.08 & 5.35 & Increasing \\
\hline \multirow[t]{2}{*}{ Udaipur } & 644 & 0.00 & 0.05 & Increasing & 304 & 0.00 & 0.018 & Increasing & 208 & 0.07 & 4.60 & Increasing \\
\hline & \multicolumn{4}{|c|}{ Annual rainfall trend (1971-2019) } & \multicolumn{4}{|c|}{ Min temperature trend $(1971-2019)$} & \multicolumn{4}{|c|}{ Max temperature trend (1971-2019) } \\
\hline
\end{tabular}

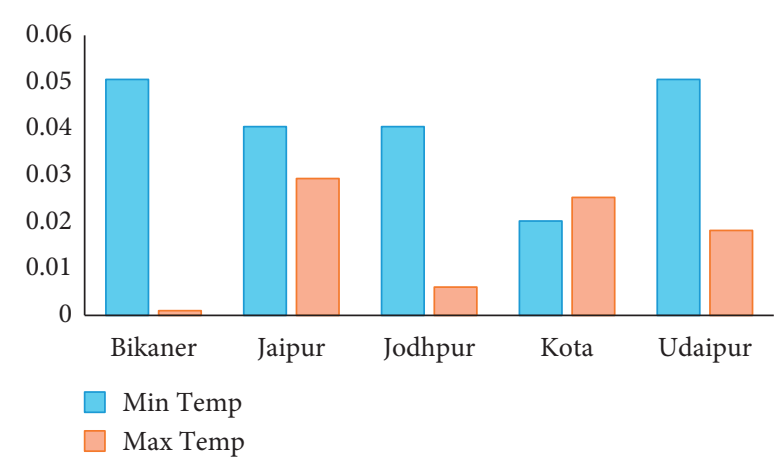

Figure 3: Sen's slope for temperature at different stations.

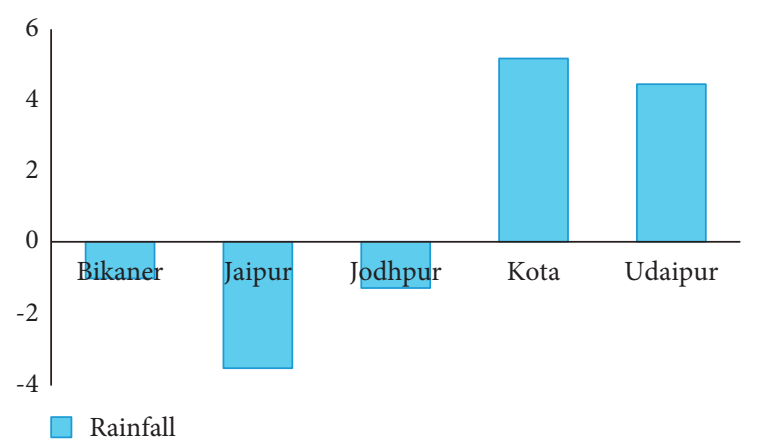

Figure 4: Sen's slope for rainfall at different stations.

temperature also showed a significant increasing trend for Jaipur, Kota, and Udaipur stations. Sen's slope values, shown in Figure 3, also show a positive trend for temperature at all the five stations.

Though, Bikaner and Jodhpur districts showed an increasing but nonsignificant trend with $P$ value of 0.57 and 0.51 , respectively. However, both positive and negative trends were identified in rainfall data. Rainfall showed a nonsignificant declining trend for Bikaner, Jaipur, and Jodhpur stations having Sen's slope of $-1.07,-3.69$, and -1.35 magnitude, respectively, while Kota (5.35) and Udaipur (4.60) exhibited an increasing trend (Figure 4). These finding confirm the results obtained by Deoli et al. [23] who also reported similar trends for temperature and rainfall in Udaipur district.

These findings clearly indicate that the global trend of climate change is persisting in the state of Rajasthan also, whose major area already falls under hot and dry climatic conditions, and this is a matter of great concern for all.

\section{Conclusion}

The trends in three major climatic parameters, namely, min and max temperature and rainfall through nonparametric approach are attempted to be investigate in the present study. Both temperature and rainfall showed considerable variation in different months as well as in the last five decades. It is evident from the data summary that the state is receiving very less to scarce rainfall which is also unevenly distributed within the whole state. Besides this, it is also showing a declining trend particularly in Bikaner, Jaipur, and Jodhpur districts. Kota and Udaipur showed an increase in rainfall, but it is not statistically significant. For min and max temperature, all the stations showed a significant positive trend. Results were confirmed by the MK test and Sen's slope estimator. In conclusion, these findings can be taken as an indicator of change in temperature and rainfall that are occurring in the state during last 50 years and can be used for future projection studies. Increasing temperature and decreasing rainfall are already a major concern for environmentalist, climatologists, farmers, policy makers, and society at large, and in such situation, the findings of this study are very imperative for an agrarian economy like ours.

\section{Data Availability}

For this study, the historical data for the year 1971-2019 (49 years) were collected for rainfall, minimum temperature, and maximum temperature for Bikaner, Jaipur, Kota, Jodhpur, and Bikaner districts of Rajasthan. The weather data from 1971 to 2014 were collected from the portal of Climate Research and Services India Meteorological Department, Pune (https://cdsp.imdpune.gov.in/), while the latest data from the period of 2015-2019 were obtained from the publication of Rainfall Statistics of India, 2015-2019 (https://hydro.imd.gov.in/hydrometweb/ (S(youz4bzdpt0j4c455zbrxgut))/landing.aspx).

\section{Conflicts of Interest}

The authors declare that they have no conflicts of interest.

\section{References}

[1] N. Subhash and A. Sikka, "Trend analysis of rainfall and temperature and its relationship over India," Theoretical and Applied Climatology, vol. 117, pp. 449-462, 2014. 
[2] F. R. Moise, A. Colman, and J. Brown, "Behind uncertainties in projections of Australian tropical climate: analysis of 19 CMIP3 models," Journal of Geophysical Research, vol. 117, 2012.

[3] M. Tanarhte, P. Hadjinicolaou, and J. Lelieveld, "Intercomparison of temperature and precipitation data sets based on observations in the Mediterranean and the Middle East," Journal of Geophysical Research, vol. 117, no. 12, 2012.

[4] S. Meshram, S. Singh, C. Meshram, R. Deo, and B. Ambade, "Statistical evaluation of rainfall time series in concurrence with agriculture and water resources of Ken River basin, Central India (1901-2010)," Theoretical and Applied Climatology, vol. 134, no. 3, pp. 1231-1243, 2018.

[5] S. Jain and V. Kumar, "Trend analysis of rainfall and temperature data for India," Current Science, vol. 102, pp. 37-49, 2012.

[6] S. Gajbhiye, C. Meshram, S. K. Singh, P. K. Srivastava, and T. Islam, "Precipitation trend analysis of Sindh River basin, India, from 102-year record (1901-2002)," Atmospheric Science Letters, vol. 17, no. 1, pp. 71-77, 2016.

[7] M. Fulekar and R. Kale, "Impact of climate change: Indian scenario," University News, vol. 48, no. 24, pp. 14-20, 2010.

[8] J. Handmer, Y. Honda, Z. Kundzewicz et al., A Special Report of Working Groups I and II of the Intergovernmental Panel on Climate Change (IPCC), Cambridge University Press, Cambridge, UK, 2012.

[9] G. B. Pant and K. Kumar, Climates of South Asia, John Wiley \& Sons, Chichester, UK, 1997.

[10] M. Arora, N. Goel, and P. Singh, "Evaluation of temperature trends over India," Hydrological Sciences Journal, vol. 50, 2005.

[11] S. Dash, R. Jenamani, S. Kalsi, and S. Panda, "Some evidence of climate change in twentieth-century India," Climatic Change, vol. 85, 2007.

[12] P. Mohammad and A. Goswami, "Temperature and precipitation trend over 139 major Indian cities: an assessment over a century," Modeling Earth Systems and Environment, vol. 5, 2019.

[13] S. Solomon, "The physical science basis," The Intergovernmental Panel on Climate Change, vol. AR4, 2007.

[14] E. Stocker, The Physical Science Basis, Cambridge University Press, Cambridge, UK, 2013.

[15] R. Khavse, N. Deshmukh, N. Manikandan, J. Kaushik, and D. Kaushk, "Statistical analysis of temperature and rainfall trend in Raipur district of Chhattisgarh," Current World Environment, vol. 10, no. 1, pp. 305-312, 2015.

[16] A. Mulugeta, D. P. Sharma, and S. Shekana, "Weather variability forecasting model through data mining techniques," International Journal of Advanced Computer Science and Applications, vol. 11, no. 9, pp. 31-41, 2020.

[17] Climate Research \& Services India Meteorological Department, https://cdsp.imdpune.gov.in/.

[18] Rainfall Statistics of India, Customized Rainfall Information System, Rainfall Statistics of India, New Delhi, India, 2015.

[19] H. B. Mann, "Nonparametric tests against trend," Econometrica, vol. 13, no. 3, pp. 245-259, 1945.

[20] M. Kendall, Rank Correlation Methods, Charles Griffin, London, UK, 1975.

[21] K. Hipel and A. McLeod, Time Series Modelling of Water Resources and Environmental Systems, Elsevier, Amsterdam, Netherlands, 1994.

[22] P. K. Sen, "Estimates of the regression coefficient based on kendall's tau," Journal of the American Statistical Association, vol. 63, no. 324, pp. 1379-1389, 1968.

[23] V. Deoli and S. Rana, "Seasonal trend analysis in rainfall and temperature for Udaipur district of Rajasthan," Current World Environment, vol. 14, no. 2, pp. 312-319, 2019. 